\title{
O ICMS ecológico em Goiás: aspectos legais e de relevância do aprimoramento dessa política
}

The ecological icms in Goiás: legal and relevant aspects of the improvement of these policies

\author{
Túlio Silva Oliveira ${ }^{1}$ (D) e Robson Rodrigues Rocha ${ }^{2}$ (D) \\ ${ }^{1}$ Universidade Federal de Goiás (UFG), mestrando pela UFG, pós-graduado pelo Instituto Brasiliense de Direito Público, email: \\ tuliolvr@gmail.com \\ ${ }^{2}$ Instituto Brasiliense de Direito Público, pós-graduado, email: robsonrochaadv@uol.com.br
}

\section{RESUMO}

O presente artigo traz um estudo sobre o ICMS ecológico, a origem, sua adoção pelo Estado de Goiás e o repasse da receita aos municípios goianos. O objetivo é mostrar o ICMS ecológico como política pública relevante e fonte de receita "extra" aos municípios goianos, que pode fomentar boas práticas de gestão voltadas à preservação ambiental. Para tanto, o artigo apresenta o arcabouço jurídico que permite a criação do ICMS ecológico, com destaque para a legislação em Goiás, o modo como se dá a habilitação para que o munícipio seja inserido no programa e os números, especialmente, nos anos de 2017 e 2018. Da análise é apresentada a conclusão à qual chegou o autor, em que mostra não só a importância da política pública, mas a necessidade de revisão da legislação a fim de se evitar distorções e para que seja alcançada maior efetividade na quantidade de municípios inseridos no repasse do ICMS ecológico.

Palavras-chave: Proteção ambiental, ICMS ecológico, Repartição de Receitas.

\begin{abstract}
This article presents a study on the ecological ICMS, origin, its adoption by the State of Goiás and the transfer of revenue to the Goiás' municipalities. The objective is to show the ecological ICMS as a relevant public policy and a source of extra revenue for municipalities in Goiás and to promote good management practices aimed at environmental preservation. Thus, the article presents the legal framework that allows the creation of the ecological ICMS, with emphasis on the legislation in Goiás, how to qualify for the municipality to be included in the program and the numbers, especially in the years 2017 and 2018 The analysis shows the conclusion reached by the author, which shows the importance of public policy, but the need to revise the legislation to avoid distortions and to achieve greater effectiveness in terms of municipalities inserted in the transfer of ecological ICMS.
\end{abstract}

Keywords: Environmental Protection. Ecological ICMS. Revenue Breakdown.

Ciências Sociais Aplicadas em Revista, v. 20, n. 38, p. 238-260, semestral, janeiro-junho, 2020. 


\section{INTRODUÇÃO}

A receita pública tem caído de forma acelerada ao mesmo tempo em que a demanda por investimentos faz o caminho inverso, o que tem levado a ineficiência dos serviços públicos de modo geral e a insatisfação dos cidadãos, sejam os serviços públicos de responsabilidade da União, Estados ou Municípios.

As mudanças climáticas são uma realidade cada dia mais evidente, como se pode comprovar pelo aquecimento global, a insatisfatória qualidade do ar, o degelo das calotas polares, os tsunamis, a escassez de água, as grandes queimadas de florestas e parques e, ainda, a extinção de plantas e animais em todos os continentes.

Da análise superficial dos dois pontos citados nos parágrafos anteriores surgiu o interesse em abordar, no presente artigo, o instituto do ICMS ecológico e suas características, como instrumento de política pública com possibilidades de aumentar a receita pública municipal sem criar um novo imposto ao mesmo tempo em que se mostra promissor na preservação do meio ambiente.

Nesse contexto, o objetivo é analisar o contexto histórico evolutivo da questão ambiental e tributária no Brasil, as competências tributárias, a repartição das receitas com foco no ICMS, sobretudo o ICMS ecológico, em decorrência do que dispõe a Constituição Federal de 1988, a implementação de forma pioneira pelo Estado do Paraná, posteriormente por demais Estados e sua adoção em Goiás por meio da Emenda Constitucional Estadual nº 40, de 2007, e regulamentado por normas infraconstitucionais.

Para tanto, serão abordadas as competências em matéria ambiental e a competência dos Estados-membros para legislar em direito tributário em conformidade com a Constituição Federal de 1988, em especial, referente ao Imposto sobre a Circulação de Mercadorias e Serviços - ICMS, o surgimento do ICMS ecológico, sua adoção pelo Estado de Goiás e a importância dessa política pública para os municípios goianos, com destaque para os critérios legais para o repasse do recurso.

Portanto, além da presente introdução, este artigo apresentará três sessões. A primeira delas trará a evolução histórica e o reconhecimento da necessidade de se tutelar o meio ambiente por meio de normas constitucionais/legais no Brasil. A segunda sessão apresentará como a questão ambiental e tributária é tratada na Constituição Federal de 1988 sob os aspectos da competência em matéria ambiental e competência tributária atribuída aos entes federativos, em especial aos Estados e Distrito Federal para instituir o Imposto Sobre a Circulação de Mercadorias e Serviços. Já na 
terceira e última sessão será abordado o ICMS ecológico, sua origem no Estado do Paraná, a adoção por outros Estados, inclusive o Estado de Goiás, o modo como o instituto do ICMS ecológico é regulado no Estado, como a repartição da receita tributária é feita e a importância dessa fonte de receita para os municípios goianos, tanto sobre o aspecto financeiro como fomento à mudança de hábitos de gestores públicos no que tange a proteção e preservação ambiental, em especial, a criação de reservas ambientais e proteção aos mananciais públicos de água.

\section{A EVOLUÇÃO HISTÓRICA DA CONSCIÊNCIA AMBIENTAL NO BRASIL}

A humanidade vive hoje o fruto da colonização, do desenvolvimento industrial, tecnológico, científico e das escolhas feitas ao longo dos séculos. Escolhas que raras vezes consideraram a capacidade de o planeta ambientalmente absorver o impacto das decisões tomadas.

Como meio ambiente é um todo indivisível e o Brasil, geográfica, política e economicamente está inserido no contexto mundial, também sofreu os impactos dessa realidade.

A colonização brasileira, iniciada ao acaso, de forma predatória, baseada na monocultura e no extrativismo rudimentar do ouro, da madeira, somado a falta de planejamento na construção das cidades, que surgiam e cresciam sem levar em conta a necessidade de redes de esgoto, água encanada, poluindo o solo e nascentes, nos trouxe a realidade presente.

Nesse sentido são as palavras de Élida Séguin (2006, p. 10), conforme se observa abaixo:

A ideia de rasgar o Brasil com caminhos fez com que as cidades nascessem como plantas selvagens, às margens de rodovias, sendo a urbanificação forma de correção do caos urbano que se instalou em decorrência da falta de planejamento.

No Brasil, a conscientização e evolução de que era preciso mudar o passado construindo um futuro diferente se deu em três fases ou momentos distintos, que são a fase de exploração desregrada, a fase da fragmentação e a fase holística, como bem ressalta (BENJAMIN, 1999).

Assim, o fato é que o Brasil se mostrou inerte durante longo período e somente no início da década de 80 o Poder Legislativo Federal começou a legislar e demonstrar preocupação com o meio ambiente de uma forma global e integrada (MILARÉ, 2014).

Parece existir razão nas palavras do autor, tendo em vista que no período citado foi editada a Lei Federal $n^{\circ}$ 6.938/81, que dispõe sobre a Política Nacional do Meio Ambiente, a qual pode ser 
considerada, em termos de legislação ambiental no Brasil, a primeira norma legal, pois definiu os conceitos, princípios, objetivos e instrumentos para a defesa do meio ambiente.

Em 1985 entrou em vigor a Lei Federal nº 7.347/85, que disciplinou a ação civil pública como instrumento apto na defesa do meio ambiente e demais direitos difusos, tornando capaz a busca do Poder Judiciário pela reparação pelos danos ao meio ambiente.

Todavia, o grande destaque na evolução da tutela ao meio ambiente foi a Constituição Federal de 1988, ao reservar um capitulo a temática ambiental, elevando o meio ambiente a bem protegido constitucionalmente.

A partir da Constituição Federal, várias outras normas foram surgindo regulamentando a previsão constitucional, com destaque para a Lei Federal n 9.605/98, a Lei de Crimes Ambientais, que dispõe sobre sanções penais e administrativas aplicáveis às condutas e atividades lesivas ao meio ambiente e passou a prever a desconsideração da personalidade da pessoa jurídica e a responsabilização penal da pessoa jurídica.

No ano de 2010 foi publicada a Lei Federal $n^{\circ}$ 12.305/2010, a qual finalmente instituiu a Política Nacional de Resíduos Sólidos, na qual institui a responsabilidade compartilhada dos geradores de resíduos, tendo como uma das propostas a prática de hábitos de consumo sustentáveis e instrumentos para propiciar o aumento da reciclagem e reutilização dos resíduos sólidos.

Apesar de todas as normas citadas acima terem sido editas pela União, Estados e Municípios também tem se empenhado nesse proposito, como o Estado de Goiás que possui leis tratando da temática ambiental, a exemplo do ICMS ecológico, com status constitucional, como política fiscal ambiental regulado por lei complementar com o propósito de oferecer aporte orçamentário aos municípios que demonstrarem práticas de gestão ambiental efetiva.

É notório que após séculos de inegáveis avanços tecnológicos, sociais, científicos e industriais e acelerado consumo, o homem percebeu que o planeta não está suportando tudo isso, que recursos naturais e renováveis os quais ele considerava infinitos, não são infinitos e nem tão renováveis assim, o que despertou na atualidade a consciência de que é preciso mudar hábitos e retroceder para continuar a existir.

Ciências Sociais Aplicadas em Revista, v. 20, n. 38, p. 238-260, semestral, janeiro-junho, 2020. 


\section{ASPECTOS NA LEGISLAÇÃO BRASILEIRA}

\subsection{ASPECTOS DAS COMPETÊNCIAS CONSTITUCIONAIS EM MATÉRIA AMBIENTAL}

Por mais que já existissem leis que abordassem a questão ambiental no Brasil, foi com a promulgação da Constituição de 1988 que o Direito Ambiental brasileiro se fortaleceu. É possível reconhecer que a Constituição Federal de 1988 foi a que, de acordo com Holthe (2010, p. 1007): "mais se preocupou com a proteção do meio ambiente, sendo apontada pela doutrina como um dos documentos mais avançados e modernos do constitucionalismo mundial, fazendo jus à afirmação de ser um 'documento especialmente ambientalista"' (apud BULOS, 2007, p. 1400 - 1401).

A Carta Magna, em seu art. 225, define o meio ambiente como o bem de uso coletivo, comum a todos, e, em capítulo próprio reforçou que é dever de cada um fazer a sua parte para proteger os recursos naturais para as presentes e futuras gerações.

Assim, a tutela ambiental necessita ser almejada em todos os níveis de governo, sendo que para evitar a invasão ou conflito de atribuições, a Constituição Federal tratou de delinear e organizar as competências em legislativa também denominada formal e administrativa ou material.

De acordo com Luís Paulo Sirvinkas (2012, p. 186):

Normas de competência são as que atribuem aos entes federados (União, Estados, Distrito Federal e Municípios) matérias gerais e especificas para melhor administrar suas unidades federativas e proporcionar bem-estar à população. Essa repartição decorre do sistema federativo.

Conforme o ordenamento legal vigente, existem duas espécies de competências e ambas partem do texto constitucional. A competência legislativa, também conhecida como formal, atribui ao ente federativo poderes para editar leis em matéria ambiental. Já a segunda competência está relacionada à questão administrativa ou material, ligada a gestão, ao efetivo exercício do poder, seja na fiscalização, no poder de polícia dos entes federativos, lhes atribuindo deveres e não liberalidades.

De acordo com a Carta Magna, em matéria ambiental, a competência formal citada acima é concorrente entre União, Estados e Distrito Federal, consoante ao que preceitua o artigo 24 da Constituição: 
Compete à União, aos Estados e ao Distrito Federal legislar concorrentemente sobre: I direito tributário, financeiro, penitenciário, econômico e urbanístico; VI - florestas, caça, pesca, fauna, conservação da natureza, defesa do solo e dos recursos naturais, proteção do meio ambiente e controle da poluição; VIII - responsabilidade por dano ao meio ambiente, ao consumidor, a bens e direitos de valor artístico, estético, histórico, turístico e paisagístico;

Ainda que o art. 24 não tenha inserido os Municípios, todavia, entende-se que isso não significa que eles não tenham competência legislativa, tendo em vista que o art. 30, inciso II, da Constituição da República estabelece sua competência para assuntos de interesse local.

Já a definição de competência concorrente é aquela que concede aos Estados e o Distrito Federal agir nos casos em que a União mantem-se inerte sobre determinadas matérias. Ressalvando a competência privativa da União de legislar, conforme art. 22 da Constituição Federal de 1988, sobre águas, energia, jazidas, minas e outros recursos minerais, populações indígenas e atividades nucleares de qualquer natureza.

No âmbito da competência concorrente, cabe à União editar normas gerais, padronizando e uniformizando a legislação. Já aos Estados cabe a edição de normas suplementares, que irão detalhar e pormenorizar a legislação geral, adaptando-as às suas realidades.

A definição do conceito de norma geral é amplamente abordada na doutrina brasileira. Assim colacionamos o apontamento de Paulo Affonso Leme Machado (2007, p 107):

A Constituição brasileira não conceitua norma geral. Resta à doutrina e a jurisprudência essa tarefa. A norma geral visa à aplicação da mesma regra em um determinado espaço territorial. A geral federal ambiental, ou em outra matéria de competência concorrente, não precisa necessariamente abranger todo o território brasileiro. Uma norma geral ambiental federal poderá dispor, por exemplo, sobre as áreas previstas no art. $225, \S 4^{\circ}$ Floresta Amazônica Brasileira, Serra do Mar, Mata Atlântica, Pantanal e Zona Costeira. A norma geral pode abranger somente um ecossistema, uma bacia hidrográfica ou somente uma espécie vegetal ou animal. A União está obrigada a inserir na norma geral o conteúdo dos acordos, tratados ou convenções internacionais já ratificados, depositados e promulgados pelo Brasil, como, evidentemente, guardar fidelidade à Constituição em vigor.

Desse modo, compreende-se que enquanto a União não editar as normas gerais, os Estados terão competência legislativa plena e a posterior edição de lei federal com norma geral suspende a eficácia da lei estadual no que lhe for contrária, como bem destaca o art. $24, \S 3^{\circ}$ da CF.

No art. 23 da Carta Magna, define a competência comum do seguinte modo:

É competência comum da União, dos Estados, do Distrito Federal e dos Municípios: III proteger os documentos, as obras e outros bens de valor histórico, artístico e cultural, os monumentos, as paisagens naturais notáveis e os sítios arqueológicos; VI - proteger o meio

Ciências Sociais Aplicadas em Revista, v. 20, n. 38, p. 238-260, semestral, janeiro-junho, 2020. 
ambiente e combater a poluição em qualquer de suas formas; VII - preservar as florestas, a fauna e a flora; IX - promover programas de construção de moradias e a melhoria das condições habitacionais e de saneamento básico; XI - registrar, acompanhar e fiscalizar as concessões de direitos de pesquisa e exploração de recursos hídricos e minerais em seus territórios;

Cumpre ressaltar, nos termos previstos no art. 21, da Constituição Federal, que a União tem competência exclusiva para executar e elaborar matérias ambientais, casos como: planos de ordenação do território e desenvolvimento socioeconômico, instituir o sistema nacional de recursos hídricos e as diretrizes de desenvolvimento urbano, incluindo habitação, saneamento básico e transportes urbanos, explorar serviços e instalações nucleares de qualquer natureza e estabelecer as áreas e as condições para o exercício da atividade de garimpagem.

Quanto à competência legislativa, quando a União edita uma norma geral, os Estados devem obediência aos seus preceitos. Já em se tratando de implementação administrativa da lei, não há hierarquia nas atuações das diferentes esferas da Administração Pública. Obedecida a Constituição Federal, não há hierarquia entre norma federal, estadual ou municipal, mas sim diferenciação de competência atribuída pela própria Carta da República.

Portanto, a temática referente ao Meio Ambiente pode ser tratada pelas três esferas da unidade federativa brasileira, diferindo apenas quanto à abrangência: União traça diretrizes gerais, Municípios tratam de interesses locais e Estados suplementam as normas gerais no que for cabível.

\subsection{ASPECTOS TRIBUTÁRIOS NA CONSTITUIÇÃO FEDERAL DE 1988}

A adoção do sistema tributário nacional e sua constitucionalização surgiram com a Emenda Constitucional no 18/65 à Constituição Federal de 1946, e posteriormente, foi adotada pela Constituição de 1967 (MORAES, 2006).

Todavia, coube a Constituição Federal de 1988 consagrar o Sistema Tributário Nacional como a principal diretriz do Direito Tributário, estabelecendo e definindo as espécies de tributos, as limitações do poder de tributar, a distribuição de competências tributárias e a repartição das receitas tributárias, caracterizando-se, pois, pela rigidez e complexidade (MACHADO, 2007).

Nesta perspectiva, Kioshi Harada em sua obra Direito Financeiro e Tributário, assim ensina (2008, p. 296):

Assim, Sistema Tributário Nacional é o conjunto de normas constitucionais de natureza tributária, inserido no sistema jurídico global, formado por um conjunto unitário e ordenado de normas subordinadas aos princípios fundamentais, reciprocamente 
harmônicos, que organiza os elementos constitutivos do Estado, que outra coisa não é senão a própria Constituição.

Já a definição de tributo, não é uniforme. Todavia, a doutrina em geral inclui em seu conceito o traço característico da coercitividade. Assim, os tributos são prestações pecuniárias compulsórias, que o Estado exige de seus súditos em virtude do seu poder de império (HARADA, 2008).

O Código Tributário Nacional, recepcionado pela Constituição Federal de 1988, com status de lei complementar, em seu art. $3^{\circ}$, define tributo como "toda prestação pecuniária compulsória, em moeda ou cujo valor nela se possa exprimir, que não constitua sanção de ato ilícito, instituída em lei e cobrada mediante atividade administrativa plenamente vinculada".

Deste modo, o tributo é um instrumento de soberania estatal, legal e social, composto pela receita oriunda de particulares, para que o Estado possa desenvolver suas atividades e necessidades, por meio desses recursos financeiros, como decorrência direta da supremacia do interesse público sobre o privado. Assim, os princípios da supremacia do interesse público sobre o interesse privado e da indisponibilidade do interesse público, são basilares dessa seara.

Em dias atuais, observa-se que o Estado se vale do tributo, não apenas como fonte de receitas para o abastecimento dos cofres públicos, mas também se utiliza da tributação para a consecução de objetivos econômicos e sociais.

A competência para legislar sobre direito tributário é a outorga de poder concedido pela Constituição Federal para que os entes federativos possam editar leis e traçarem regras sobre o exercício do poder de tributar.

Consoante a Constituição Federal, em seu art. 24, a competência para legislar sobre direito tributário é concorrente entre União, os Estados e o Distrito Federal. Já o art. 30 da Constituição Federal estabelece a competência dos Municípios para legislarem sobre assuntos de interesse local e suplementar a legislação federal e estadual no que lhe couber.

Conforme explicitado no nosso Sistema Constitucional Tributário o gênero tributo, se divide em 3 espécies: impostos, taxas e contribuições.

Todavia, de acordo com o entendimento de Kiyoshi Harada (2007, p. 300) o leque é mais amplo. Vejamos:

Entendemos que a matéria deve ser examinada à luz do Sistema Tributário Nacional vigente e estudada em conformidade com os princípios constitucionais tributários, o que amplia o campo de análise, extrapolando o Capítulo I, do Titulo VI da CF (arts. 145 a 162), 
visto que, aqueles princípios se acham espalhados por toda a Constituição. Em termos de direito positivo brasileiro, temos as seguintes espécies tributárias: impostos, taxas, contribuições de melhorias, empréstimo compulsório, contribuições sociais do art. 149 da CF e contribuições sociais do art. 195 da CF.

Desta forma, em qualquer dos entendimentos, tendo como ponto central a discussão sobre o Imposto sobre a Circulação de Mercadorias e Serviços, qualquer das classificações doutrinárias ou legais, não influenciam na análise, posto que o tributo em questão é pacífico sob quaisquer entendimentos.

\subsection{ASPECTOS DO IMPOSTO SOBRE A CIRCULAÇÃO DE MERCADORIAS E SERVIÇOS - ICMS}

Na esteira de uma classificação qualitativa, Ricardo Lobo Torres (2013, p. 371) assim diz: "os tributos vinculados são os tributos devidos em decorrência de uma prestação estatal em favor do contribuinte; vinculadas são as taxas e as contribuições; não vinculados, os impostos”.

O imposto sobre operações relativas à circulação de mercadorias e sobre prestações de serviços de transporte interestadual e intermunicipal e de comunicação foi introduzido pela Constituição Federal de 1988, ao realizar modificações no extinto ICM. Antes de competência impositiva federal, incorporando a ele os serviços de transporte interestadual e intermunicipal e de comunicação, resultando no ICMS como conhecemos hoje.

Na Carta Magna vigente, o imposto está previsto no art. 155, inciso II, no qual diz que a competência é dos "Estados e ao Distrito Federal instituir impostos sobre operações relativas à circulação de mercadorias e sobre prestações de serviços de transporte interestadual e intermunicipal e de comunicação, ainda que as operações e as prestações se iniciem no exterior"

Cabe mencionar ainda a Lei Complementar $n^{\circ}$ 87/96, conhecida Lei Kandir, que regulamentando norma geral, dispõe sobre o ICMS e, em seu art. $2^{\circ}$, elenca as operações sujeitas à incidência do imposto.

O sistema tributário brasileiro aborda com destaque a distinção entre imposto direto e imposto indireto. O primeiro gradua diretamente a soma devida por determinado contribuinte, em conformidade com sua capacidade contributiva, exemplo claro dessa definição é o Imposto sobre a Renda. Já o segundo, o imposto indireto, de modo diverso, associa o ônus tributário a um evento jurídico ou material e não dispõe de um parâmetro direto para apurar a capacidade econômica do contribuinte, podemos citar com destaque o ICMS (TORRES, 2013).

Ciências Sociais Aplicadas em Revista, v. 20, n. 38, p. 238-260, semestral, janeiro-junho, 2020. 
Em linhas gerais, podemos citar, em relação ao ICMS, que é um imposto não cumulativo, tendo em vista a possibilidade de compensação de créditos e débitos. Assim, é cobrada apenas a carga tributária que caminha pela cadeia de produção.

O ICMS é, também, um imposto seletivo, uma vez que poderá ter alíquotas diferentes, de acordo com o grau de essencialidade para o dia a dia da população, em que produtos e bens considerados supérfluos têm alíquotas maiores, enquanto produtos essenciais, como medicamentos e alimentos da cesta básica, por exemplo, possuem alíquotas menores.

No que se refere ao transporte interestadual e intermunicipal, a Carta da República não especificou o tipo de transporte que o ICMS abarca como fato gerador, se de passageiros, mercadorias, valores ou outros bens. Essa omissão da Constituição leva ao entendimento que a incidência do imposto se dá sobre todas essas situações.

Cumpre mencionar, por fim, que o lançamento do imposto se dá por homologação, de modo que o sujeito passivo calcula o valor a ser recolhido e antecipa seu pagamento, sem a necessidade previa de exame da autoridade estatal (ALEXANDRE, 2009).

O ICMS no Brasil é regido por 27 leis diferentes, considerando que cada Estado-membro e o Distrito Federal tem competência para ditar suas regras e alíquotas. É o principal tributo estadual e sua receita, na maioria dos Estados, é responsável pela maior entrada de recursos nos cofres públicos.

\section{O ICMS ECOLÓGICO}

\subsection{ORIGEM DO ICMS ECOLÓGICO E SUA FINALIDADE}

O acelerado processo de degradação ambiental, ocorrido sobretudo nas últimas décadas, tem levado a debates e a necessidade da adoção de medidas que busquem conter a devastação ou o ritmo de devastação do meio ambiente que temos testemunhado. Proteger mares, rios, florestas e a fauna se tornou algo fundamental. O aquecimento de nosso planeta é algo real, fruto do processo de destruição provocado pelo homem, já tendo sido apontado por especialistas como um dos principais motivos para os grandes acidentes ambientais ocorridos em todo o planeta.

Políticas de proteção ao meio ambiente existem diversas, algumas mais efetivas, outras não. Políticas relacionadas à tributação foram adotadas inicialmente em países da Escandinávia 
(Noruega, Suécia e Dinamarca), com o objetivo de conter a onda de devastação e em decorrência dos resultados.

No Brasil, políticas semelhantes têm sido desenvolvidas pela União, Estados e Municípios. Dentre elas, encontra-se com destaque e relevância a criação do chamado "ICMS ecológico" pelos Estados que surge como instrumento inovador de política ambiental fiscal.

A possibilidade de implementação do ICMS ecológico surgiu em decorrência do que prevê a Constituição Federal de 1988, em seu art. 158, § único, inciso II, no qual dispõe que até um quarto do imposto do ICMS, será repassado pelos Estados aos municípios, de acordo com o que dispuser lei estadual ou, no caso dos Territórios, lei federal.

Aqui colacionamos as palavras de Wilson Loureiro (2008, p. 10), um dos principais especialistas no tema, que assim escreveu:

O ICMS ecológico é um instrumento que aproveita a oportunidade criada pelo federalismo fiscal brasileiro, qual seja, o do repasse de recursos financeiros a entes federados, sem que a instituição que recebe tais recursos perca sua autonomia político-administrativa. Essa oportunidade se ancora no disposto no inciso II, do artigo 158 da Constituição Federal, que define aos Estados poder de legislar sobre até 1/4 do percentual a que os municípios têm direito de receber do Imposto sobre Circulação de Mercadorias e Serviços (ICMS).

A política de benefícios e compensações por condutas ambientais positivas decorre do princípio jurídico do protetor-recebedor, reconhecido na doutrina e previsto na Lei Federal $\mathrm{n}^{\circ}$ $12.305 / 2010$.

Destacada definição nos apresenta o professor Frederico Amado (2017, p. 66-67), a respeito deste princípio do direito ambiental, vejamos:

Trata-se do princípio que institui benefícios e compensações por serviços ambientais, em favor daqueles que atuam na defesa do meio ambiente. Estes benefícios podem ocorrer por meio de concessão de créditos subsidiados, redução de tributos ou instituição de isenções tributárias. Objetiva-se promover a justiça ambiental, viabilizando-se o desenvolvimento sustentável. Possui previsão no art. $6^{\circ}$ da Lei de Resíduos Sólidos.

Assim, surgiu o ICMS ecológico, inicialmente no Estado do Paraná, no ano de 1989, sendo adotado atualmente por 18 dos 27 entes da federação, de acordo com o portal do ICMS ecológico, fundado em 2009, com a missão de divulgar informações sobre o tema e as medidas adotadas nos estados e municípios do país.

No Estado do Paraná, o projeto do ICMS ecológico surgiu como medida de compensação aos municípios diante das restrições legais impostas em razão das unidades de conservação e mananciais de água em seus territórios, as quais impediam a expansão de atividades econômicas.

Ciências Sociais Aplicadas em Revista, v. 20, n. 38, p. 238-260, semestral, janeiro-junho, 2020. 
Tempos depois, em decorrência da experiência prática, a legislação foi alterada, deixando de ser apenas uma compensação, para se tornar um incentivo econômico real, passando a premiar os municípios que realizaram boas práticas de gestão de suas áreas naturais.

Portanto, sem criar um novo imposto, mas direcionando a repartição da receita por critérios delineados, criou-se um mecanismo que permite ao Estado influenciar positivamente no processo de sustentabilidade dos municípios, premiando com aumento de receita, e consequente melhoria do orçamento, aqueles que, praticando ações de gestão ambiental, aprimorem a preservação dos bens naturais.

Além do Paraná, experiências de destaque implementadas por outros Estados brasileiros merecem ser mencionados. Também merece destaque o Estado de Minas o qual ofereceu importantes contribuições ao avanço do ICMS ecológico, quando em 1995 editou sua legislação sobre o tema, ao incluir nela critérios alternativos. Além das unidades de conservação, incluiu a busca de solução para tratamento do lixo, proteção ao patrimônio cultural, educação.

O mais novo Estado da federação, Tocantins foi quem mais ousou na elaboração de sua legislação sobre o ICMS ecológico, ao utilizar variáveis quantitativas e qualitativas no processo de cálculo dos índices indo além ao utilizar outros critérios como a aprovação de legislação ambiental local e dotação orçamentária que resultem na estruturação da política municipal do meio ambiente e da agenda21 local, controle de queimadas e combate a incêndios, promoção da conservação e do manejo dos solos, saneamento básico e conservação da água e coleta e destinação do lixo.

Desse modo, buscou-se, com a inclusão desses critérios na redistribuição do ICMS, o envolvimento efetivo na prática de condutas mais efetiva do poder público local e das entidades da sociedade civil, no esforço pela melhoria da qualidade de vida, minimização das desigualdades sociais e erradicação da pobreza, pelo exercício da cidadania.

Apresentadas a origem e finalidade do instituto, além de ações efetivas em alguns dos estados brasileiros, na próxima sessão, abordaremos a realidade do Estado de Goiás, os passos dados e como está a efetividade dessa política fiscal ambiental em nosso Estado.

\subsection{O ICMS ECOLÓGICO NO ESTADO DE GOIÁS}

Segundos dados do IBGE, o Estado de Goiás possui área territorial aproximada de 340.086 km², um total de 246 municípios e a economia está baseada na pecuária, agricultura, confecção, comércio, mineração, metalurgia e madeireira. Todavia, a agropecuária é a atividade com maior 
destaque. Tudo isso, graças a terras férteis, água abundante, clima favorável, agregado a inserção da tecnologia na produção, o que elevou Goiás ao patamar dos grandes exportadores de grãos e um dos maiores rebanhos do país.

Diante disso Goiás passou a enfrentar o desafio de conseguir fomentar a expansão agroindustrial e pecuária ao tempo em que deve buscar a sustentabilidade ambiental, sobretudo com a preservação do bioma cerrado, um dos mais ricos em biodiversidade no planeta, além das importantes bacias hidrográficas que nascem ou cortam o Estado.

O avanço da legislação ambiental ocorrida em outros estados da federação e da necessidade de fomentar a economia dos municípios goianos e ainda incentivar a proteção ambiental, levou Goiás a também movimentar-se politicamente para editar sua legislação e implantar o ICMS ecológico.

Após aproximadamente 16 anos da edição da norma paranaense, a emenda constitucional $\mathrm{n}^{\mathrm{o}} 40$, de 30 de maio de 2007, foi promulgada. A EC inseriu, no parágrafo $1^{\circ}$, inciso III, do art. 107 da constituição estadual, disposição sobre a repartição das receitas tributárias do ICMS. Desta forma, 5\% da receita passou a ser distribuído aos municípios goianos, na proporção do cumprimento de exigências estabelecidas em lei estadual específica, relacionadas com a fiscalização, defesa, recuperação e preservação do meio ambiente.

Desta maneira, ainda que o Estado de Goiás tivesse elevado a matéria ao status de norma constitucional, faltava a edição de uma lei tutelasse o assunto, o projeto de lei ordinária iniciado em 2007 não teve êxito, pois a matéria deveria ser tratada por lei complementar. Assim, foi sancionada a Lei Complementar Estadual no 90, de 22 de dezembro de 2011, posteriormente regulamentada pelo Decreto $n^{\circ} 8.147$, de 08 de abril de 2014.

Portanto, a Constituição Estadual estabeleceu no seu art. 107, $\S 1^{\circ}$, os percentuais que compõem o Índice de Participação dos Municípios - IPM na repartição das receitas do ICMS. O índice será calculado utilizando-se os seguintes percentuais: 85\% pelo Valor Adicionado, 10\% divididos em partes iguais entre todos os municípios e $5 \%$ na proporção do cumprimento de exigências estabelecidas em lei estadual específica, relacionadas com a fiscalização, defesa, recuperação e preservação do meio ambiente.

A Lei Complementar n ${ }^{o}$ 90/11 condicionou a participação dos municípios na divisão do percentual de 5\% ao preenchimento de pelo menos 3 dos 9 critérios ambientais especificados no inciso I, do parágrafo único, do art. $4^{\circ}$ da referida lei. Além disso, criou um sistema de pontuação para graduar a participação dos municípios no cálculo do ICMS ecológico.

Ciências Sociais Aplicadas em Revista, v. 20, n. 38, p. 238-260, semestral, janeiro-junho, 2020. 
O percentual de 5\% é calculado da seguinte forma: $3 \%$ para quem cumprir pelo menos 6 critérios, $1,25 \%$ para quem cumpriu pelo menos quatro critérios e $0,75 \%$ para quem cumpriu pelo menos três critérios descritos na lei.

A apuração de quais municípios cumpriram os critérios definidos pela lei é feita pela SECIMA, que anualmente encaminha ao Conselho Deliberativo dos Índices de Participação dos Municípios/COINDICE ICMS, uma relação dos municípios que cumpriram os critérios e o número de critérios cumprido por cada um deles. Daí, compete a Secretaria Executiva do COINDICE/ICMS o cálculo do "Índice pelos Critérios Ecológicos” (SEFAZ-GO, 2018).

De acordo com o site da Secretaria de Estado de Fazenda de Goiás, a partir do momento que se tem os "Índices Ecológicos", eles são somados ao "Índice da Parte Fixa" e ainda ao "Índice da Participação do Município no ICMS - IPM” de cada município de Goiás. O IMP será o índice utilizado pelo Estado de Goiás para a distribuição da parcela de $25 \%$ (vinte e cinco por cento) do ICMS pertencentes aos municípios. Este índice que viabiliza ao Estado a entregar as parcelas da receita tributária, previstas na Carta Magna e pertencentes aos municípios goianos.

O que se observa em Goiás é a complexidade para se atingir o percentual do repasse do ICMS aos municípios. Sendo que o ICMS ecológico, engloba o repasse total do ICMS, não constituindo um repasse a parte, nem tão pouco é especificado no repasse quanto desse valor se refere a ICMS ecológico, o que não contribui em nada para o crescimento dessa política fiscal ambiental. Assim não os obriga a aplicar parte dessa transferência em políticas ambientais, sob o argumento de que as transferências de tributos estão previstas na Constituição Federal e não estabelecem vinculação de receitas, o que em tese, também seria inconstitucional (SEFAZ-GO, 2018).

Não bastasse o percentual, a forma do cálculo não é clara em dizer exatamente quanto cada município recebe a título de repasse do ICMS ecológico. Vejamos a explicação extraída do site da Secretaria de Estado da Fazenda de Goiás:

Muitos municípios indagam quanto recebem a título de ICMS ecológico. Mais uma vez salientamos que não há um repasse de valores específico para o chamado "ICMS ecológico", uma vez que esse percentual está contido no Índice de Participação de cada município goiano na repartição do ICMS, que é único e indivisível. Contudo, caso o interessado deseje saber o valor específico de cada critério e, em específico, do ICMS ecológico, deverá seguir os seguintes passos:

1. O interessado deverá localizar a Resolução com o "Índice Ecológico" vigente e o total do ICMS transferido aos Municípios em cada repasse. Para tanto deverá consultar no site www.sefaz.go.gov.br/ banner COINDICE/link - Relatório de Distribuição de ICMS Bolão Semanal - Por Município. Em seguida, deve selecionar a cidade, mês e ano que 
tenha interesse em consultar. Na terceira coluna consta o número da Resolução correspondente àquele repasse. Na quarta coluna consta o total de ICMS repassado aos municípios naquela semana.

2. Consultar a Resolução no site www.sefaz.go.gov.br/ banner COINDICE/ Download das Resoluções dos Índices de Participação dos Municípios. Na Resolução desejada constará a planilha com os Índices dos Municípios. O “Índice Ecológico" está na penúltima coluna.

3. Multiplicar o "Valor do Bolão" pelo "Índice Ecológico" do município consultado e, em seguida, dividir o resultado por 100(cem).

4. Ex: Repasse Semanal do ICMS: R\$ 100.000.000,00

Índice Ecológico Municipal A: 0,0750000

Pela explicação descrita, nota-se a complexidade para que se tenha conhecimento sobre qual o percentual alcançado por cada município goiano em relação ao ICMS ecológico, o que prejudica o propósito com que foi criado, ao dificultar o acesso a informação relacionada aos índices.

Portanto, é fato que a população dos munícipios e entidades ambientais e demais interessados ao não terem acesso as informações compromete o desenvolvimento da política pública do ICMS, por não gerar o engajamento do cidadão no processo e prejudicar a cobrança do cidadão e a fiscalização dos órgãos de controle e fiscalização.

\subsection{REQUISITOS PARA O REPASSE E RELEVÂNCIA DO ICMS ECOLÓGICO PARA OS MUNICÍPIOS GOIANOS}

A importância do ICMS ecológico para os municípios goianos deve ser analisada sobre a dupla face, quais sejam: do aumento da receita que já é limitada frente as despesas orçamentárias municipais e do ganho em qualidade de vida da população por meio de práticas efetivas de sustentabilidade e conservação das áreas de mananciais e reservas ambientais.

De acordo com dados obtidos no site da Federação Goiana dos Municípios de Goiás - FMG, houve um aumento de $62 \%$ na quantidade de municípios contemplados com o ICMS ecológico em 2018, se comparado com o ano de 2017. No ano de 2017, apenas 76 municípios recebiam o teto do recurso, sendo que, em 2018, foram 115 municípios que se encaixam no percentual máximo.

Além do aumento na quantidade de municípios, também houve aumento do número de critérios da Lei Complementar $n^{\circ}$ 90/2011 atendidos pelos municípios o que lhes permitiram alcançar um percentual maior do repasse do ICMS ecológico. Abaixo um gráfico que demonstra essa evolução nos anos de 2017 e 2018 :

Ciências Sociais Aplicadas em Revista, v. 20, n. 38, p. 238-260, semestral, janeiro-junho, 2020. 
Gráfico 1 - Municípios contemplados em 2017 e 2018

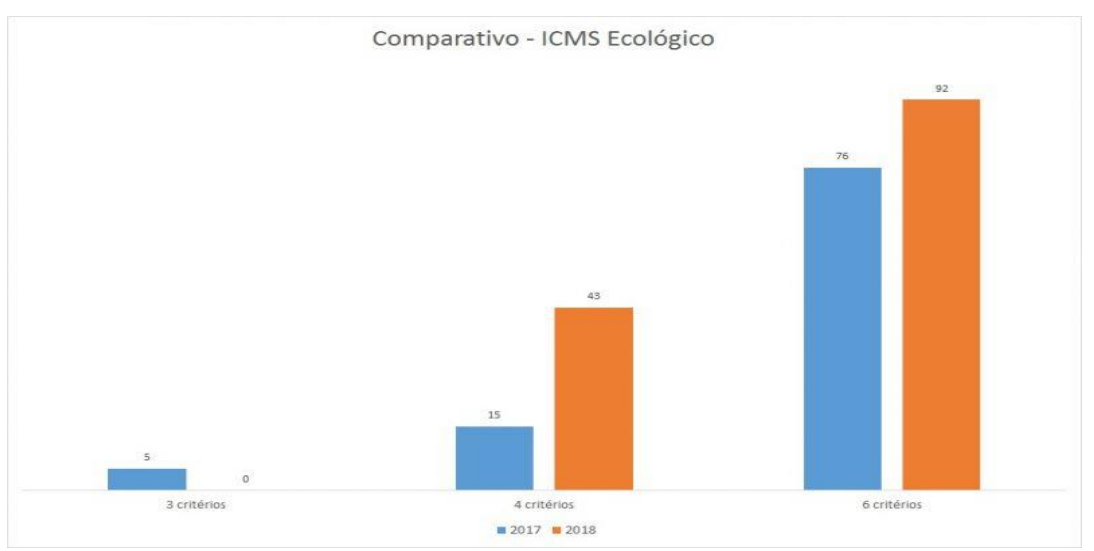

Fonte - Federação Goiana de Municípios.

Esse aumento no percentual chamou a atenção de órgãos de controle e fiscalização. $O$ Ministério Público do Estado de Goiás passou a acompanhar com maior dedicação e tem feito levantamento de dados e reuniões com gestores públicos, a princípio para se informar e orientar sobre as práticas de gestão realizadas.

Neste sentido, cabe trazer abaixo as palavras do promotor de justiça do Ministério Público do Estado de Goiás, extraída do site da instituição, Delson Leone Júnior, Coordenador do Centro de Apoio Operacional do Meio Ambiente - CAOMA, que aponta a importância e seriedade da destinação e aplicação efetiva da receita do ICMS ecológico, além do papel preponderante do órgão nessa fiscalização ao dizer:

Em tempos de crise hídrica, de descumprimento imotivado da Política Nacional de Resíduos Sólidos e de tantas outras mazelas ambientais, parece-me mais que apropriado o atual momento para o Ministério Público se debruçar, de forma acurada, sobre essa fonte inexplorada de receita, físcalizando não apenas a fidelidade e a execução das informações prestada por cada município contemplado, mas também a sua aplicação correta, de acordo com os anseios legais, visando garantir a continuidade ininterrupta dos programas, políticas públicas e ações implementados em todo Estado de Goiás.

Conforme dispõe a Lei Complementar $n^{\circ}$ 90, de 22 de dezembro de 2011, em Goiás, para que o município seja contemplado com repasses do ICMS ecológico, inicialmente, é preciso que abriguem em seus territórios unidades de conservação ambiental, ou que sejam diretamente por elas influenciados ou, ainda, aqueles possuidores de mananciais para abastecimento público.

A norma explicita ainda que municípios possuidores de mananciais para abastecimento público são aqueles em cujos territórios se situam bacias hidrográficas, no todo ou em parte, com mananciais abastecedores de municípios limítrofes. 
O detalhamento dos conceitos, condutas e modo de operacionalização da matéria, prevista na Lei Complementar $n^{\circ}$ 90/2011, foi regulamentado por meio do Decreto $n^{\circ} 8.147$, de 08 de abril de 2014, no qual elenca as definições de unidades conservação ambiental para fins de solicitação ao repasse do percentual de ICMS ecológico e as condutas e programas pelas quais as autoridades competentes devem se orientar.

Conforme dispõe a legislação goiana sobre o tema, para que um município possa requerer o ICMS ecológico é necessário ter em seu território uma unidade de conservação, devidamente registrada no Cadastro Estadual de Unidades de Conservação, ou ser diretamente influenciado por ela, ou ainda, possuir mananciais de abastecimento público de municípios confrontantes. Além desses pré-requisitos, o município interessado precisa atender aos seguintes critérios ambientais e de conservação do meio ambiente, elencados nas alíneas do inciso I, do art. $4^{\circ}$, da Lei Complementar $n^{\circ}$ 90/2011:

a) ações de gerenciamento de resíduos sólidos, inclusive lixo hospitalar e resíduos da construção civil - coleta, transporte, tratamento e destinação dos resíduos sólidos, aterro sanitário, incineração, reciclagem e compostagem;

b) ações efetivas de educação ambiental, na zona urbana e rural, nas escolas e grupos da sociedade organizada, instituídas por intermédio de lei municipal e/ou programas específicos;

c) ações de combate e redução do desmatamento, com a devida fiscalização e comprovação da efetiva recuperação de áreas degradadas - reflorestamento;

d) programas de redução do risco de queimadas, conservação do solo, da água e da biodiversidade;

e) programa de proteção de mananciais de abastecimento público;

f) identificação de fontes de poluição atmosférica, sonora e visual, e comprovação das medidas adotadas para a minimização dessas práticas;

g) identificação das edificações irregulares, bem como a comprovação das medidas adotadas para sua adequação às normas de uso e ocupação do solo;

h) programas de instituição e proteção das unidades de conservação ambiental;

i) elaboração de legislação sobre a política municipal de meio ambiente, incluindo a criação do Conselho Municipal do Meio Ambiente e do Fundo Municipal do Meio Ambiente, obedecidas as peculiaridades locais, respeitadas a legislação federal e estadual sobre o assunto;

Portanto, depende do atendimento aos critérios citados acima a inclusão dos municípios na política do ICMS ecológico e o percentual ao qual terão direito na repartição da receita tributária dele decorrente.

Conforme explicitado na Lei Complementar $\mathrm{n}^{\circ}$ 90/2011, os percentuais do repasse do ICMS ecológico, serão feitos aos municípios que possuírem gestão ambiental condizente com os padrões de desenvolvimento sustentável e conservação da biodiversidade e dos recursos naturais, conforme 
o número de itens atendidos por cada município, daqueles elencados nos itens de letra a ao item de letra i, do inciso I, do art. $4^{\circ}$, da Lei. Vejamos:

Tabela 1 - Número mínimo de critérios e percentual de repasse do ICMS ecológico respectivo

\begin{tabular}{c|c}
\hline $\begin{array}{c}\text { Número mínimo de critérios conforme a Lei } \\
\text { Complementar } \mathbf{n}^{\mathbf{0}} \mathbf{9 0 / 2 0 1 1}\end{array}$ & $\begin{array}{c}\text { Percentual do repasse do ICMS ecológico referente } \\
\text { ao atendimento do número mínimo de critérios da } \\
\text { Lei Complementar } \mathbf{n}^{\mathbf{0}} \mathbf{9 0 / 2 0 1 1}\end{array}$ \\
\hline 06 & $3 \%$ \\
\hline 04 & $1,25 \%$ \\
\hline 03 & $0,75 \%$ \\
\hline
\end{tabular}

Fonte: Lei Complementar no 90/2011

Conforme informações obtidas no site da Federação Goiana de Municípios - FGM, nos anos de 2017 e 2018, a distribuição do ICMS ecológico ocorreu conforme números abaixo:

Tabela 2 - Repartição da receita do ICMS ecológico nos anos de 2017 e 2018

\begin{tabular}{c|c}
\hline $\mathbf{2 0 1 7}$ & $\mathbf{2 0 1 8}$ \\
\hline Não receberam -150 municípios & Não receberam -111 municípios \\
\hline 03 critérios -05 municípios & 03 critérios - nenhum \\
\hline 04 critérios -15 municípios & 04 critérios -43 municípios \\
\hline 06 critérios -76 municípios & 06 critérios -92 municípios \\
\hline
\end{tabular}

Fonte: Lei Complementar n ${ }^{\circ}$ 90/2011

Ainda que tenha aumentado substancialmente o número de municípios que elevaram o índice de participação na distribuição do percentual do ICMS ecológico, a quantidade de munícipios que não recebem o repasse ainda é muito alta, como também é alto o número de municípios goianos que não atingiram o percentual máximo do repasse, sobretudo tendo em vista as características dos municípios do Estado de Goiás.

Observa-se que os 9 itens elencados na Lei Complementar $n^{\circ}$ 90/2011, todos são de fácil implementação, inclusive sem exigir do gestor público grandes investimentos orçamentários, o que mostra que o número de municípios alcançados pelo benefício do ICMS ecológico ainda é muito baixo de acordo com os dados apresentados acima.

A aprovação da Lei Complementar n 148/2018, alterou ao disposto na Lei Complementar $n^{\circ}$ 90/2011 para que fosse considerado "regular o município que teve reconhecida suas práticas ambientais pela Secretaria do Meio Ambiente, Recursos Hídricos, Infraestruturas, Cidades e Assuntos Metropolitanos (SECIMA-GO, 2018) no ano base de 2017, mantendo-se a mesma classificação de cumprimento de requisitos contidos no art. 4, I, alíneas "a", "b", “c”, "d”, “e”, “f”, “g”, "h”, “i” e “j”, da Lei Complementar no 90, de 2011”. 
Nota-se pelo disposto no $\S 1^{\circ}$, da Lei Complementar $n^{\circ} 148 / 2018$, que parece ter ocorrido decisão estritamente política eleitoreira, pela simples leitura do texto, em que a norma diz que "o disposto no caput se aplica somente para fins de recebimento da respectiva parcela do ICMS no exercício de 2019".

Conforme informação do site da Federação Goiana de Municípios o número de municípios que serão contemplados pelo ICMS ecológico em 2019 saltou de 156 para 166, após a edição da Lei Complementar $n^{\circ}$ 148/2018.

Esse tipo de crescimento do número de municípios alcançados não é o que no parecer salutar para o programa do ICMS ecológico, nem tão pouco a aprovação de leis como a citada acima irá contribuir para o objetivo fim que se busca com a política pública aqui apresentada. Ao contrário, é preciso crescer em número de municípios que tenham direito ao repasse do ICMS ecológico, em Goiás, mas atendendo ao sério espírito da lei, que é o de fomentar a economia dos municípios aos "premiá-los” por boas e saudáveis práticas de gestão pública ambiental.

\section{CONSIDERAÇÕES FINAIS}

É fato que a oportunidade trazida pela Constituição Federal de 1988, ao dispor em seu art. $158, \S$ único, inciso II, que até um quarto do imposto ICMS será repassado pelos Estados aos Municípios de acordo com o que dispuser lei estadual ou, no caso dos Territórios, lei federal, foi primordial para o surgimento do ICMS ecológico, inicialmente no Estado do Paraná.

Ao longo dos anos, a iniciativa paranaense tem sido adotada por outros estados da federação e a política pública tem sido aprimorada com o objetivo de gerar receitas tributárias extras aos munícipios sem criar um novo imposto e, ao mesmo tempo, motivar o gestor público municipal a adotar práticas de sustentabilidade, proteção e conservação ambiental.

Conforme foi apresentado, em Goiás a regulamentação do ICMS ecológico foi iniciada em 2007 por meio da aprovação da Emenda Constitucional n 40, de 30 de maio de 2007, e posteriormente por leis e decreto regulamentando a matéria.

Pelo estudo da legislação goiana em vigor, com base nos dados e informações obtidos junto aos órgãos estaduais e de fiscalização, além de entidades ligadas à questão, torna-se possível conclusões relevantes em relação ao tema deste artigo.

A história da colonização goiana não é diferente da brasileira, marcada pela devastação e exploração dos recursos naturais de forma rudimentar e predatória. As desigualdades regionais

Ciências Sociais Aplicadas em Revista, v. 20, n. 38, p. 238-260, semestral, janeiro-junho, 2020. 
mostram que os 246 municípios do Estado de Goiás possuem realidades econômicas distintas, cujo repasse decorrente do ICMS ecológico para muitos deles é fonte de receita relevante para o orçamento municipal, em que as despesas elevadas impedem a adoção de políticas públicas importantes, como a de preservação ambiental.

Todavia, a adesão ao ICMS ecológico no Estado de Goiás ainda baixa considerando o número de municípios que ainda não recebem do repasse. Os municípios que mais carecem de receitas são aqueles que não conseguem atender os requisitos exigidos pela lei ou não demonstram interesse em participar do programa.

Como forma de valorizar a política pública do ICMS ecológico e conseguir um maior número de municípios participantes da "fatia do bolo", é importante que o governo estadual divulgue de forma ampla a existência e as vantagens da adesão ao programa.

A legislação estadual carece de revisão. Os valores repassados decorrentes do ICMS ecológico exigem um cálculo complexo, o que prejudica a transparência e dificulta ao cidadão comum o acesso aos valores reais oriundos do ICMS ecológico (SEFAZ-GO, 2018).

A repartição da receita e os percentuais definidos precisam ser revistos. No modo atual, o gestor municipal que atende os requisitos e se habilita, tende a se mobilizar para que o número de municípios não aumente e a parcela do repasse diminua, fato passível de acontecer entre municípios vizinhos que poderiam ser parceiros no desenvolvimento, um contrassenso à finalidade da norma.

Quanto aos municípios, compete a eles a elaboração de leis sobre políticas ambientais, criação de conselhos municipais de meio ambiente, fundos municipais de meio ambiente e realização de audiências e consultas públicas à população como medidas essenciais a serem executadas pelos agentes políticos, sobretudo naqueles municípios que ainda não recebem o repasse do ICMS ecológico.

Por fim, é preciso citar a edição da Lei Complementar nº 148, de 04 de dezembro de 2018, sancionada quando este artigo já estava em elaboração, a qual alterou os critérios, por questões injustificadas, considerando habilitados ao repasse do recurso do ICMS ecológico em 2019 àqueles municípios habilitados no ano base 2017, os quais não tinham atendido os requisitos legais no prazo limite para habilitação, o que prejudica a seriedade do programa e frustra a expectativa de receita maior daqueles municípios que haviam cumprido as exigências legais.

Com a edição da lei acima mencionada, o número de municípios que terão direito ao repasse do ICMS ecológico em 2019 saltou de 156 para 166 (FGM, 2019), fato que não merece ser 
comemorado pelo modo como ocorreu, mas que não deve gerar desânimo àqueles municípios que lutam e acreditam em políticas públicas importantes, tais como o ICMS ecológico.

\section{REFERÊNCIAS}

AMADO, Frederico. Direito Ambiental 5 ed. Salvador: Editora Juspodivm, 2017

BENJAMIN, Antônio Herman V. Introdução ao direito ambiental brasileiro. Revista de Direito Ambiental. São Paulo: Editora Revista dos Tribunais, abril-junho 1999. v. 14. Ano 4.

BRASIL. Constituição da República Federativa do Brasil 1988, de 05 de outubro de 1988. Disponível em <http://www.planalto.gov.br/ccivil_03/constituicao/constituicaocompilado.htm>. Acesso em fev. 2019.

Lei Complementar $n^{\circ}$ 87, de 13 de setembro de 1996. Dispõe sobre o imposto dos Estados e do Distrito Federal sobre operações relativas à circulação de mercadorias e sobre prestações de serviços de transporte interestadual e intermunicipal e de comunicação, e dá outras providências. $\quad$ (LEI KANDIR). Disponível em: <http://www.planalto.gov.br/ccivil_03/leis/LCP/Lcp87.htm>. Acesso em: fev. 2019.

Lei $n^{0}$ 6.938, de 31 de agosto de 1981. Dispõe sobre a Política Nacional do Meio Ambiente, seus fins e mecanismos de formulação e aplicação, e dá outras providências. Disponível em: 〈http://www.planalto.gov.br/ccivil_03/leis/L6938.htm> . Acesso em: fev. 2019.

Lei $n^{\circ}$ 9.605, de 12 de Fevereiro de 1998. Dispõe sobre as sanções penais e administrativas derivadas de condutas e atividades lesivas ao meio ambiente, e dá outras providências. Disponível em: <http://www.planalto.gov.br/ccivil_03/leis/L9605.htm>. Acesso em fev. 2019.

Lei $n^{\circ}$ 12.305, de 2 de Agosto de 2010. Institui a Política Nacional de Resíduos Sólidos; altera a Lei $n^{0}$ 9.605, de 12 de fevereiro de 1998; e dá outras providências. Disponível em: <http://www.planalto.gov.br/ccivil_03/_Ato2007-2010/2010/Lei/L12305.htm>. Acesso em: fev. 2019.

FEDERAÇÃO GOIANA DE MUNICÍPIOS. Com movimentação da FGM e AGM, COÍNDICE aprova valores aos contemplados do ICMS Ecológico. Disponível em: <https://www.fgmgo.org.br/2018/12/06/com-movimentacao-da-fgm-e-agm-coindice-aprova-icms-ecologico/> Acesso em: 20 de fev. 2019

Confira a lista dos municípios beneficiados com o ICMS Ecológico 2018. <https://www.fgm-go.org.br/2017/11/30/confira-a-lista-dos-municipios-beneficiados-com-oicms-ecologico-2018/> Acesso em: 12 dez. 2018.

GOIÁS (Estado). Constituição (1988). Emenda Constitucional nº 40, de 30 de maio de 2007. Altera

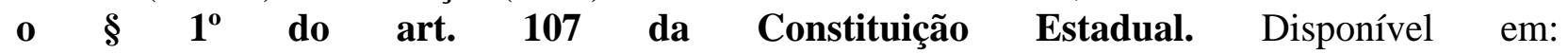
<http://www.gabinetecivil.go.gov.br/pagina_emendas.php?id=73 >. Acesso em: fev. 2019. 
Decreto $\mathrm{n}^{\circ} 8147$, de 08 de abril de 2014. Regulamenta a Lei Complementar $\mathbf{n}^{\circ} \mathbf{9 0}$, de 22 de dezembro de 2011. Disponível em: <http://www.gabinetecivil.go.gov.br/decretos/numerados/2014/decreto_8147.htm> . Acesso em: mar. 2019.

Lei Complementar $n^{\circ}$ 90, de 22 de dezembro de 2011. Regulamenta o disposto no inciso III do $\$ 1^{\circ}$ do art. 107 da Constituição Estadual, acrescido pela Emenda Constitucional $\mathbf{n}^{\circ}$ 40, de 30 de maio de 2007, e dá outras providências. Disponível em: <http://www.gabinetecivil.goias.gov.br/leis_complementares/2011/lei_complementar_n90.htm> Acesso em: fev. 2019.

Lei Complementar $n^{\circ} 148$, de 04 de dezembro de 2018. Dispõe sobre os critérios para a apuração do ICMS ecológico de que trata a Lei Complementar $n^{\circ} 90$, de 22 de dezembro de 2011, para o exercício que especifica. Disponível em: http://www.gabinetecivil.go.gov.br/pagina_leis.php?id=23071. Acesso em: mar. 2019.

HOLTHE, Leo Van. Direito Constitucional. 6 ed. Salvador: Editora Juspodivm, 2010

ICMSCOLOGICO.ORG.BR. Histórico do ICMS-E no Brasil. Disponível em: $<\mathrm{http}$ //www.icmsecologico.org.br/site/index.php?option=com_content\&view=article\&id=52\&Ite mid=82>. Acesso em: 21 fev. 2019.

LOUREIRO, Wilson. ICMS ecológico, uma experiência brasileira de pagamentos por serviços ambientais. Belo Horizonte: Conservação Internacional - São Paulo: Fundação SOS Mata Atlântica - Curitiba : The Nature Conservancy (TNC), 2008.

MACHADO, Paulo Affonso Leme. Direito Ambiental Brasileiro. São Paulo, Malheiros Editores, 2007.

MILARÉ, Édis. Direito do Ambiente. 9. ed. São Paulo: Revista dos Tribunais, 2014.

MINISTÉRIO PÚBLICO DO ESTADO DE GOIAS. MP busca reforçar fiscalização da utilização de recursos do ICMS Ecológico na proteção ambiental $<$ http://www.mpgo.mp.br/portal/noticia/mp-busca-reforcar-fiscalizacao-da-utilizacao-de-

recursos-do-icms-ecologico-na-protecao-ambiental\#.XIaZdLhv-M8> Acesso: em 15 de dez. 2018.

MOARES, Alexandre de. Direito Constitucional, 32 ed. São Paulo: Atlas, 2016.

SECIMA-GO. ICMS Ecológico. Disponível em: <http://www.secima.go.gov.br/meio-ambiente-erecursos-h\%C3\%ADdricos/icms-ecol\%C3\%B3gico.html> Acesso em: 15 dez. 2018.

SEFAZ-GO. Esclarecimentos sobre o ICMS Ecológico. Disponível em: http://www.sgc.goias.gov.br/upload/arquivos/2017-05/esclarecimentos-sobre-o-icmsecolOgico.pdf . Acesso em: 18 de dez. 2018.

SÉGUIN. Élida. Direito ambiental: nossa casa planetária, 3 ed. Rio de Janeiro, 2006. 
SIRVINKAS, Luís Paulo. Manual de Direito Ambiental. 15. ed. São Paulo: Saraiva, 2017. TORRES, Ricardo Lobo. Curso de Direito Financeiro e Tributário, 19 ed. Renovar, 2013. 